\title{
Serine Proteases and Vaccines against Leishmaniasis: A Dual Role
}

Suzana Passos Chaves ${ }^{3}$, Daniel Claudio Oliveira Gomes ${ }^{4}$, Salvatore Giovanni De-Simone ${ }^{6,7}$, Bartira Rossi-Bergmann ${ }^{5}$, and Herbert Leonel de Matos Guedes ${ }^{1,2, *}$

${ }^{1}$ Laboratório de Inflamação, Grupo de Imunologia e Vacinologia, Instituto de Biofísica Carlos Chagas Filho, Universidade Federal do Rio de Janeiro, 21941 -902 Rio de Janeiro, RJ, Brazil

${ }^{2}$ Núcleo Multidisciplinar de Pesquisa UFRJ - Xerém em Biologia (NUMPEXBIO), Polo Avançado de Xerém-Universidade Federal do Rio de Janeiro, 25245-390 Duque de Caxias, RJ, Brazil

${ }^{3}$ Laboratório de Imunoparasitologia, Universidade do Rio de Janeiro, Campus Macaé, 27965-045, Macaé, RJ. Brazil

${ }^{4}$ Laboratório de Imunobiologia, Núcleo de Doenças Infecciosas/ Núcleo de Biotecnologia, Universidade Federal do Espírito Santo, 29043-900 Vitória- ES, Brazil

${ }^{5}$ Laboratório de Imunofarmacologia, Instituto de Biofísica Carlos Chagas Filho, Universidade Federal do Rio de Janeiro, 21941-902 Rio de Janeiro, RJ, Brazil

${ }^{6}$ Centro de Desenvolvimento Tecnológico em Saúde (CDTS)/Instituto Nacional de Ciencia e Tecnologia de Inovação em Doenças de Populações Negligenciadas (INCT-IDPN), 21045-900 Rio de Janeiro, RJ, Brazil

${ }^{7}$ Laboratório de Bioquímica de Proteínas e Peptídeos Instituto Oswaldo cruz (IOC). Fundação Oswaldo Cruz (FIOCRUZ), Rio de Janeiro, RJ, Brazil

"Corresponding author: Herbert Leonel de Matos Guedes, 1Laboratório de Inflamação, Grupo de Imunologia e Vacinologia, Instituto de Biofísica Carlos Chagas Filho, Universidade Federal do Rio de Janeiro, 21941-902 Rio de Janeiro, RJ, Brazil, Tel: 02139386507; E-mail: herbert@biof.ufrj.br

Received date: 21 October 2014; Accepted date: 16 January 2015; Published date: 20 January 2015

Copyright: ( 2015 Chaves SP, et al. This is an open-access article distributed under the terms of the Creative Commons Attribution License, which permits unrestricted use, distribution, and reproduction in any medium, provided the original author and source are credited.

\begin{abstract}
Serine proteases are involved in several biochemical processes that are essential for the biology of pathogens, including Leishmania sp. Considering their importance, an interest in serine proteases for vaccine development against leishmaniasis has been raised. As targets, these enzymes have demonstrated a dual role in a vaccine against leishmaniasis, both protective and a counter-protective, depending on the conditions that they are evaluated. In this work, serine proteases or inhibitors of them that have been used as components of vaccines to Leishmania sp. are presented, aiming to disseminate the knowledge gained about these proteases and their potential in potential vaccine against leishmaniasis.
\end{abstract}

Keywords: Serine proteases; Vaccine; intramuscular immunization; Intranasal immunization; Counter-protective; Protection; TGF-beta

\section{Abbreviations}

LaAg: L. amazonensis promastigotes antigens; LaE: L. amazonensis extract from amastigotes; SP: Serine Proteases; LaSP-Sol: Soluble Serine proteases from $L$. amazonensis promastigotes; LaSP-Ex: Extracellular serine proteases from $L$. amazonensis promastigotes supernatant of culture; pSP: Secreted serine protease from $L$. donovani; Lmjsp: Signal Peptidase I from L. major.

\section{Introduction}

Leishmaniasis is a protozoonose caused by the etiologic agent Leishmania sp. It presents two clinical forms, cutaneous, which varies from a painless, localized and self-healing skin lesion to necrotizing forms in mucosal tissue, and a visceral form that can compromise the function of the liver and spleen with a high incidence of lethality [1]. The disease is found mainly in tropical countries of Asia, Africa, South America and Mediterranean Europe. Current estimates suggest that nearly 11 million people are infected around the world [1]. The World Health Organization (WHO) due to its epidemiology and socioeconomic impact classifies it as a neglected tropical disease.

The clinical treatments available for leishmaniasis are based on antimonial drugs and amphotericin B, which have serious collateral effects that include cardiotoxicity and nephrotoxicity, respectively. In addition, their high cost and the lack of patients adhering to the long course of treatment required has made them less than ideal options for controlling leishmaniasis [2]. Unfortunately, there is no vaccine approved for human use against leishmaniasis despite the observation of protective immunity acquired following natural infections, suggesting that the production of an effective vaccine is feasible [3]. Leishvacin ${ }^{\oplus}$, which is composed of whole-killed promastigotes of $L$. amazonensis, was extensively studied for use as a vaccine in humans. Immunization with Leishvacin ${ }^{\oplus}$ does lead to conversion in the Montenegro skin test and induces IFN- $\gamma$ responses in human volunteers [4]. However, the vaccination failed in a controlled phase III clinical trial in Colombia [5]. Three veterinary vaccines have been approved and are available against canine visceral leishmaniasis, one in Europe and two in Brazil [6]. These vaccines have inspired the development of other forms for a human vaccine with one currently in phase of clinical trials, known as Leish-111F, which consists of a multisubunit recombinant protein that has MPL-SE as its adjuvant $[7,8]$.

In the search for new targets for the development of antileishmanial drugs and vaccines, knowledge of the parasite biology and the mechanisms involved with the parasite-host interactions are extremely important. Within this framework, leishmania proteases have been described as having a crucial role in parasite survival and infectivity since their activities are necessary for processing exogenous proteins as nutrients [9] and in the invasion of host cells and tissues [10].

Among the defined proteases, serine proteases represent an important group of enzymes with numerous biological functions [11]. From the sequencing of the L. major genome, a number of distinct serine proteases have been identified: (i) subtilisin-like, an S9 family 
member that also includes prolyloligopeptidase (POP), peptidyl-1 dipeptidase IV and oligopeptidase B (OPB), (ii) a type I signal peptidase (SPase I), (iii) a lysosomal serine carboxypeptidase, (iv) a $26 \mathrm{~S}$ regulatory proteasome subunit, (v) a nucleoporin homolog and (vi) an orthologous of the rhomboid-like intramembranous serine peptidase family [12]. From the L. amazonensis genome, two others of interest are; (vii) Oligopeptidase B [13] and (viii) Oligopeptidase B2 [14].

Among these, subtilisin-like, Oligopeptidase B and SPase I have been studied for their contribution in parasite biology or for hostparasite interactions. Deletion of subtilisin in $L$. donovani reduced parasite differentiation in vitro along with virulence in hamster and murine infection models [15]. Oligopeptidase B deficient L. major parasites were less capable of infecting and surviving in macrophages in vitro, but showed a similar virulence as controls in vivo [16]. Oligopetidase B, along with a new member called have been identified in L. amazonensis [13,14], however, their biological roles are unknown. Attempts to create null mutants of SPase I have been unsuccessful, suggesting that this enzyme is crucial to survival. Heterozygote mutants in L. major have shown a decreased capacity to infect in vitro and the lesions developed in an in vivo model with $\mathrm{BALB} / \mathrm{c}$ infected mice were less severe than controls [17].

\begin{tabular}{|c|c|c|}
\hline Source & Specie & References \\
\hline \multicolumn{3}{|l|}{ Leishmania amazonensis } \\
\hline Serine oligopeptidase & $101 \mathrm{kDa}$ & [18] \\
\hline $\begin{array}{l}\text { SP purified from aqueous } \\
\text { extract }\end{array}$ & $68 \mathrm{kDa}$ & {$[19,20]$} \\
\hline $\begin{array}{l}\text { SP from a detergentsoluble } \\
\text { extract }\end{array}$ & $60 \mathrm{kDa}$ and $45 \mathrm{kDa}$ & [21] \\
\hline SP from cell free supernatant & $110 \mathrm{kDa}$ & {$[22,23]$} \\
\hline \multicolumn{3}{|l|}{ Leishmania braziliensis } \\
\hline SP from a aqueous extract & $60 \mathrm{kDa}$ and $45 \mathrm{kDa}$ & [24] \\
\hline $\begin{array}{l}\text { SP from a detergentsoluble } \\
\text { extract }\end{array}$ & $\begin{array}{l}130 \mathrm{kDa}, 83 \mathrm{kDa}, 74 \\
\mathrm{kDa} \text { and } 30 \mathrm{kDa}\end{array}$ & [24] \\
\hline $\begin{array}{l}\text { SP from cell free } \\
\text { supernatant }\end{array}$ & $\begin{array}{l}62 \mathrm{kDa}, 59 \mathrm{kDa}, 57 \mathrm{kDa} \text {, } \\
49 \mathrm{kDa} \text { and } 35 \mathrm{kDa}\end{array}$ & [24] \\
\hline \multicolumn{3}{|l|}{ Leishmania chagasi } \\
\hline $\begin{array}{l}\text { SP from a aqueous extract } \\
\text { (LCSII) }\end{array}$ & $\begin{array}{l}105 \mathrm{kDa}, 66 \mathrm{kDa} \text {, and } \\
60 \mathrm{kDa}\end{array}$ & [25] \\
\hline $\begin{array}{l}\text { SP from a detergentsoluble } \\
\text { extract (LCSI) }\end{array}$ & $60 \mathrm{kDa}$ and $58 \mathrm{kDa}$ & [25] \\
\hline $\begin{array}{l}\text { SP from cell free supernatant } \\
\text { (LCSIII) }\end{array}$ & $76 \mathrm{kDa}$ and $68 \mathrm{kDa}$ & [25] \\
\hline \multicolumn{3}{|l|}{ Leishmania donovani } \\
\hline Intracellular SP & $58 \mathrm{kDa}$ & [26] \\
\hline $\begin{array}{l}\text { SP from cell free } \\
\text { supernatant }\end{array}$ & $115 \mathrm{kDa}$ & {$[27,28]$} \\
\hline
\end{tabular}

Table 1: Identified serine proteases from Leishmania spp.
In addition to the proteases identified by sequence analysis, several proteases have been isolated from promastigotes extracts using chromatography or affinity- chromatography based on binding to aprotinin (Table 1). To date, their identities remain to be determined, which is a priority for complementing the genome-based data to improve our understanding of the complete serine protease profile functioning within the genus Leishmania.

\section{The Counter-Protective Effect of Serine Protease}

Several studies have demonstrated a protective, anti-leishmanial role for serine protease inhibitors during treatments for infections. These studies demonstrated that serine protease activity could be directly related to host susceptibility to infection. The underlying mechanisms for how serine protease activity enhances susceptibility to infection are unknown. Below, we described serine proteases or serine protease activity related to susceptibility of infection.

\section{TLCK treated $L$. braziliensis and $L$. donovani}

$\mathrm{N}$-p-tosyl-L-lysine-chloromethyl ketone (TLCK) is a potent serine protease inhibitor. TLCK treatment of $L$. braziliensis and $L$. donovani parasites was used in a vaccine model for protection against homologous infection events. Initially, hamsters were immunized with L. braziliensis (LB) that were exposed to TLCK in culture then challenged with an infection with $L$. braziliensis amastigotes. A gradual proliferation of lymphocytes $\mathrm{B}$ and $\mathrm{T}$ from lymph nodes that was stimulated by mitogens and a higher response to concanavalin $\mathrm{A}$ were observed. In addition, no parasites were located in the lymph nodes after 6 weeks of infection with nodules that were 4 times smaller than those in control hamsters. For $L$. donovani, the preimmunization of hamsters with treated parasites led to survival for over a year after challenge whereas of the survival period of nonimmunized mice was 5 months [29]. This was the first study to address the importance of serine proteases for vaccines against leishmaniasis.

\section{Whole $L$. amazonensis antigens from promastigotes $(\mathrm{LaAg})$ and from amastigotes $(\mathrm{LaE})$}

A role for serine proteases to modulate the immune response of hosts was suggested by observations following the use of whole parasite antigens as an innoculm. When LaAg, which is composed of antigens from whole $L$. amazonensis promastigotes, was associated to Corynebacterium parvum and used for immunization, induced protection against L. amazonensis infection in C57Bl10 mice [30]. However, LaAg administrated to Rhesus monkeys via a subcutaneous route showed an increase in experimental infections with follow up challenges with $L$. amazonensis despite the induction of a higher IFNgamma release following immunization [31]. In a $B A L B / c$ mice cutaneous model, $\mathrm{LaAg}$ administered via intramuscular injections also increased the animal susceptibility to infection together with a positive regulation of TGF-beta overcoming the IFN-gamma [32].

To isolate the role of serine proteases in the observed aggravation of infection caused by $\mathrm{LaAg}$, antigens were pre-treated with proteases inhibitors $(\mathrm{LaAg}+\mathrm{SPi})$ prior to their use as a vaccine in $\mathrm{BALB} / \mathrm{c}$ mice [33]. In comparison to control mice, vaccinated mice developed lesions more slowly and displayed a lower parasite load suggesting an improved protection that was related to a decrease in IFN-gamma, TNF- alpha, IL-10 and TGF-beta during infection. 
Page 3 of 5

A similar effect was observed in the pre-vaccination treatment when using whole $L$. amazonensis antigen from amastigotes named $L$. amazonensis amastigote extract (LaE) followed by a challenge with $L$. braziliensis [34]. The increase of susceptibility of infection in immunized mice was dependent on the maintenance of serine protease activity. These results suggest a conserved serine protease present in promastigotes and amastigotes that are related to immunomodulation that can enhance the disease progression for Leishmania infection.

\section{Soluble serine proteases from Leishmania amazonensis (LaSP-Sol)}

The first soluble serine protease fraction (LaSP-Sol) was purified by Silva- Lopez et al. [19]. The major protease band displayed a molecular weight of $68 \mathrm{KDa}$ with a number of other minor components. This fraction from LaSP-Sol of $L$. amazonensis was demonstrated to be from membranes of intracellular compartments similar to endocytic/ exocytic elements [20].

Following vaccination with LaSP-Sol and a subsequent challenge with parasites, the in vitro proliferation of lymphocytes isolated from lymph nodes produced IL-4, IL-10 and TGF-beta in comparison to non-vaccinated mice (seven days post infection). This suggested that LaSP-Sol induced an immune response with a Th2 profile and/or activation of regulatory $\mathrm{T}$ cells. However, a comparison between effects using LaSP-Sol to $\mathrm{LaAg}$ in $\mathrm{BALB} / \mathrm{c}$ mice immunized intramuscularly showed a similar profile in lesions and parasite burden compared to non-vaccinated mice [34].

Through these results, it is possible to hypothesize that a possible mechanism for an increase in the susceptibility to a Leishmania infection is related to serine protease activity. In support of this hypothesis, it was observed that the application of LaAg or LaSP-Sol increased TGF-beta in vitro $[32,33]$. Proteases can convert latent TGFbeta in active TGF-beta [35]. It has been shown that cysteine peptidase from $L$. chagasi also can enzymatically convert TGF-beta to active form [36,37]; yet, the pre-treatment of LaAg with cysteine peptidase inhibitor was not as effective as the pre-treatment with serine protease inhibitor to overcome the counter-protective effect of LaAg [34]. Since TGF-beta can be related to T cell activity [38-40], it could explain the failure of this vaccination approach within our model system, which is in contrast the success observed in another model, the Shistosoma manasoni vaccination [31]. This hypothesis is summarized in Figure 1.

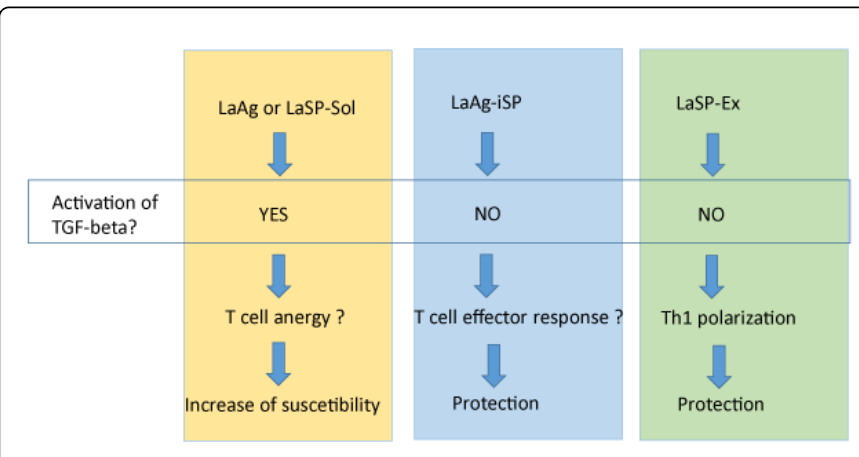

Figure 1: Activation of TGF-beta.

\section{Vaccines Using Serine Proteases as Antigens}

Some serine proteases have been evaluated as possible antigens for the development of a vaccine against leishmaniasis that are discussed below.

\section{Antigen P8}

The first serine proteases evaluated as antigen for vaccine was the P8 antigen from $L$. pifanoi. The association of P8 antigen with $C$. parvum was observed to fully protect $B A L B / c$ mice from infection by L. pifanoi and partially against L. amazonensis. In CBA/J mice, full protection was seen against infections with $L$. amazonensis [42]. This protection was most likely mediated by a Th1 immune response according to the higher levels of gamma interferon produced [42]. The characterization of P8 antigen showed a serine protease immunodominant component with $56 \mathrm{kDa}$ [43].

\section{Signal Peptidase I (Lmjsp)}

Using the type I signal peptidase (Lmjsp) cloned from L. major, a recombinant protein was created to probe for specific antibodies in the sera of patients that had an acute disease or had recovered from cutaneous and visceral leishmaniasis. Independent of their disease state, all patient sera was reactive to Lmjsp [44]. Considering its immunoreactivity, Lmjsp was tested as an antigen within three types of vaccines against $L$. major, DNA/DNA, Protein/Protein and DNA/ Protein. All forms of vaccines induced a Th1 profile. When protection against infections by Leishmania was evaluated, the DNA/DNA approach was observed to be more effective than the other two approaches with a reduction of $81 \%$ in the parasite load [45].

\section{Extracellular Serine proteases (LaSP-Ex) from $L$. amazonensis}

An extracellular serine protease fraction (LaSP-Ex) was purified from parasite culture supernatants for the first time by Silva-Lopez et al [22]. A major serine protease of $56 \mathrm{kDa}$ was detected. Through immunohistochemistry, it was localized in the flagelar pocket, cytoplasmic vesicles of promastigotes and other structures that appeared similar to the megasomes of amastigotes. A complete purification and characterization of this protein determined that the enzyme is displayed as a $110 \mathrm{kDa}$ complex in non-reducing condition [23]. It should be noted that other proteins are present in the LaSP-EX preparation after aprotinin-affinity chromatography purification.

The secretion of the $56 \mathrm{kDa}$ suggested that it could be recognized by the host immune system during an infection and a potential vaccine candidate $[22,23]$. Using immune cells from mice infected for 7-days, stimulation with LaSP-Ex did not increase TGF- $\beta$ production and inhibited spontaneous IL-10 production [46]. Vaccination with LaSPEx via an intranasal delivery was able to control lesion growth and parasite load in $\mathrm{BALB} / \mathrm{c}$ mice infected with $L$. amazonensis. In addition, isolated spleen cells from mice vaccinated with LaSP-Ex (7 days) and stimulated with LaAg produced IFN- $\gamma$, lower levels of IL-4 and IL-10 in comparison to controls and beta TGF was not modulated that suggested a systemic Th1 response profile. In the footpad, there was a reduction in the normally higher levels of gamma IFN and IL-12 with a decrease in TGF- $\beta$, suggesting that the mechanism of LaSP-Ex protection is induction of Th1 profile and inhibition of TGF-beta in vivo [46]. 


\section{Secreted serine protease (pSP) from $L$. donovani}

A similar serine protease was found in the supernatant culture of $L$. donovani with the same molecular weight of $115 \mathrm{KDa}$ [27] and with the same localization, mainly in flagelar pockets by immunohistochemistry [28]. The expression of the protease was correlated to a high virulence for the parasite and to the metacyclic stage of $L$. donovani promastigotes [28]. When pSP was evaluated as a vaccine against $L$. donovani infection, protection was only obtained when it was associated with IL-12 as an adjuvant, which led to an increase in IFN- $\gamma$ and TNF- $\alpha$ with a decrease in IL-4 and IL-10 after vaccination [47].

\section{Conclusion and Perspectives}

In this review, different formulations were considered for their capacity to induce protection against the wide range of different Leishmania strains responsible for infections in endemic regions. The treatment with serine protease inhibitor appears to be a possible approach to improve the efficacy of the most studied vaccine, LaAg, which is similar to Leishvaccine ${ }^{\infty}$. The addition of specific antigens to vaccine preparations could lead to the development of more effective protection. From the analysis of P8 antigen, LaSP-Ex, pSP and Lmjsp, each demonstrated a capacity to induce protection. Further investigations are needed to determination which serine protease class is represented and their specific biological function that are essential to understand their role in the life cycle of parasite and during infection. Furthermore, other proteins are present in the LaSP-Ex, sSP and Lmjsp that could contribute to their effects and require determination through genomic and proteomic studies. These characterizations can allow the development of the next generation of vaccines that include recombinants proteins and a combination of different serine proteases. Ultimately, these evaluations could allow for the development of a strong vaccine candidate that can induce protection against multiple strains of Leishmania parasites.

\section{Acknowledgments}

Financial support: CNPq, FAPERJ and CAPES.

\section{References}

1. Alvar J, Vélez ID, Bern C, Herrero M, Desjeux P, et al. (2012) Leishmaniasis worldwide and global estimates of its incidence. PLoS One 7: e35671.

2. Mohapatra S (2014) Drug resistance in leishmaniasis: Newer developments. Trop Parasitol 4: 4-9.

3. Kumar R, Engwerda C (2014) Vaccines to prevent leishmaniasis. Clin Transl Immunology 3: e13.

4. De Luca PM, Mayrink W, Alves CR, Coutinho SG, Oliveira MP, et al. (1999) Evaluation of the stability and immunogenicity of autoclaved and nonautoclaved preparations of a vaccine against American tegumentary leishmaniasis. Vaccine 17: 1179-1185.

5. Vélez ID, Gilchrist K, Arbelaez MP, Rojas CA, Puerta JA, et al. (2005) Failure of a killed Leishmania amazonensis vaccine against American cutaneous leishmaniasis in Colombia. Trans R Soc Trop Med Hyg 99: 593-598.

6. Otranto D, Dantas-Torres F (2013) The prevention of canine leishmaniasis and its impact on public health. Trends Parasitol 29: 339-345.

7. Chakravarty J, Kumar S, Trivedi S, Rai VK, Singh A, et al. (2011) A clinical trial to evaluate the safety and immunogenicity of the LEISH-
F1+MPL-SE vaccine for use in the prevention of visceral leishmaniasis. Vaccine 29: 3531-3537.

8. Vélez ID, Gilchrist K, Martínez S, Ramírez-Pineda JR, Ashman JA, et al. (2009) Safety and immunogenicity of a defined vaccine for the prevention of cutaneous leishmaniasis. Vaccine 28: 329-337.

9. Rosenthal PJ (1999) Proteases of protozoan parasites. Adv Parasitol 43: 105-159.

10. Roggwiller E, Bétoulle ME, Blisnick T, Braun Breton C (1996) A role for erythrocyte band 3 degradation by the parasite gp76 serine protease in the formation of the parasitophorous vacuole during invasion of erythrocytes by Plasmodium falciparum. Mol Biochem Parasitol 82: 13-24.

11. Rawlings ND, Waller M, Barrett AJ, Bateman A (2014) MEROPS: the database of proteolytic enzymes, their substrates and inhibitors. Nucleic Acids Res 42: D503-509.

12. Besteiro S, Williams RA, Coombs GH, Mottram JC (2007) Protein turnover and differentiation in Leishmania. Int J Parasitol 37: 1063-1075.

13. De Matos-Guedes HL, Duarte Carneiro MP, de Oliveira Gomes DC, Rossi-Bergmann B, De-Simone SG (2007) Oligopeptidase B from Leishmania amazonensis: molecular cloning, gene expression analysis and molecular model. Parasitol Res 101: 865-875.

14. De Matos Guedes HL, de Carvalho RSN, Gomes DCO, Rossi-Bergmann B, De-Simone SG (2008) Oligopeptidase B-2 from Leishmania amazonensis with an unusual C-terminal extension. Acta Parasitol 53: 197-204.

15. Swenerton RK, Knudsen GM, Sajid M, Kelly BL, McKerrow JH (2010) Leishmania subtilisin is a maturase for the trypanothione reductase system and contributes to disease pathology. J Biol Chem 285: 31120-31129.

16. Munday JC, McLuskey K, Brown E, Coombs GH, Mottram JC (2011) Oligopeptidase B deficient mutants of Leishmania major. Mol Biochem Parasitol 175: 49-57.

17. Taheri T, Salmanian AH, Gholami E, Doustdari F, Zahedifard F, et al. (2010) Leishmania major: disruption of signal peptidase type I and its consequences on survival, growth and infectivity. Exp Parasitol 126: 135-145.

18. De Andrade AS, Santoro MM, de Melo MN, Mares-Guia M (1998) Leishmania (Leishmania) amazonensis: purification and enzymatic characterization of a soluble serine oligopeptidase from promastigotes. Exp Parasitol 89: 153-160.

19. Da Silva-Lopez RE, Giovanni-De-Simone S (2004) Leishmania (Leishmania) amazonensis: purification and characterization of a promastigote serine protease. Exp Parasitol 107: 173-182.

20. Morgado-Díaz JA, Silva-Lopez RE, Alves CR, Soares MJ, Corte-Real S, et al. (2005) Subcellular localization of an intracellular serine protease of 68 $\mathrm{kDa}$ in Leishmania (Leishmania) amazonensis promastigotes. Mem Inst Oswaldo Cruz 100: 377-383.

21. Da Silva Lopez RE, De Simone SG (2004) A serine protease from a detergent-soluble extract of Leishmania (Leishmania) amazonensis. $\mathrm{Z}$ Naturforsch C 59: 590-598.

22. Silva-Lopez RE, Coelho MG, De Simone SG (2005) Characterization of an extracellular serine protease of Leishmania (Leishmania) amazonensis. Parasitology 131: 85-96.

23. Silva-Lopez RE, Morgado-Díaz JA, Alves CR, Côrte-Real S, GiovanniDe-Simone S (2004) Subcellular localization of an extracellular serine protease in Leishmania (Leishmania) amazonensis. Parasitol Res 93: 328-331.

24. Guedes HL, Rezende JM, Fonseca MA, Salles CM, Rossi-Bergmann B, et al. (2007) Identification of serine proteases from Leishmania braziliensis. Z Naturforsch C 62: 373-381.

25. Da Silva-López RE, dos Santos TR, Morgado-Díaz JA, Tanaka MN, de Simone SG (2010) Serine protease activities in Leishmania (Leishmania) chagasi promastigotes. Parasitol Res 107: 1151-1162.

26. Choudhury R, Das P, De T, Chakraborti T (2010) Immunolocalization and characterization of two novel proteases in Leishmania donovani: 
Citation: Chaves Sp, Gomes DCO, De-Simone SG, Rossi-Bergmann B, de Matos Guedes HL (2015) Serine Proteases and Vaccines against Leishmaniasis: A Dual Role. J Vaccines Vaccin 6: 264. doi:10.4172/2157-7560.1000264

Page 5 of 5

putative roles in host invasion and parasite development. Biochimie 92: 1274-1286.

27. Choudhury R, Bhaumik SK, De T, Chakraborti T (2009) Identification, purification, and characterization of a secretory serine protease in an Indian strain of Leishmania donovani. Mol Cell Biochem 320: 1-14.

28. Choudhury R, Das P, Bhaumik SK, De T, Chakraborti T (2010) In situ immunolocalization and stage-dependent expression of a secretory serine protease in Leishmania donovani and its role as a vaccine candidate. Clin Vaccine Immunol 17: 660-667.

29. O'Daly JA, Cabrera Z (1986) Immunization of hamsters with TLCKkilled parasites induces protection against Leishmania infection. Acta Trop 43: 225-236.

30. Mayrink W, Santos GC, Toledo Vde P, Guimaraes TM, Machado-Coelho $\mathrm{GL}$, et al. (2002) Vaccination of $\mathrm{C} 57 \mathrm{BL} / 10$ mice against cutaneous Leishmaniasis using killed promastigotes of different strains and species of Leishmania. Rev Soc Bras Med Trop 35: 125-132.

31. Kenney RT, Sacks DL, Sypek JP, Vilela L, Gam AA, et al. (1999) Protective immunity using recombinant human IL-12 and alum as adjuvants in a primate model of cutaneous leishmaniasis. J Immunol 163 4481-4488.

32. Pinheiro RO, Pinto EF, Lopes JRB, de Matos Guedes HL, Fentanes RF, et al. (2005) TGF- $\beta$ associated enhanced susceptibility to Leishmaniasis following 22 intramuscular vaccination of mice with Leishmania amazonensis antigens. Microb Infect 7: 1317-1323.

33. De Matos Guedes HL, Pinheiro RO, Chaves SP, De-Simone SG, RossiBergmann B (2010) Serine proteases of Leishmania amazonensis as immunomodulatory and disease-aggravating components of the crude LaAg vaccine. Vaccine 28: 5491-5496.

34. Silva VM, Larangeira DF, Oliveira PR, Sampaio RB, Suzart P, et al. (2011) Enhancement of experimental cutaneous leishmaniasis by Leishmania molecules is dependent on interleukin-4, serine protease/esterase activity, and parasite and host genetic backgrounds. Infect Immun 79: 1236-1243.

35. Jenkins $G$ (2008) The role of proteases in transforming growth factorbeta activation. Int J Biochem Cell Biol 40: 1068-1078.

36. Somanna A, Mundodi V, Gedamu L (2002) Functional analysis of cathepsin B-like cysteine proteases from Leishmania donovani complex. Evidence for the activation of latent transforming growth factor beta. J Biol Chem 277: 25305-25312.

37. Gantt KR, Schultz-Cherry S, Rodriguez N, Jeronimo SM, Nascimento ET, et al. (2003) Activation of TGF-beta by Leishmania chagasi: importance for parasite survival in macrophages. J Immunol 170: 2613-2620.
38. Pinheiro RO, Pinto EF, Benedito AB, Lopes UG, Rossi-Bergmann B (2004) The T-cell anergy induced by Leishmania amazonensis antigens is related with defective antigen presentation and apoptosis. An Acad Bras Cienc 76: 519-527.

39. Song S, Yuan P, Wu H, Chen J, Fu J, et al. (2014) Dendritic cells with an increased PD-L1 by TGF- $\beta$ induce T cell anergy for the cytotoxicity of hepatocellular carcinoma cells. Int Immunopharmacol 20: 117-123.

40. Saini C, Ramesh V, Nath I (2014) Increase in TGF- $\beta$ secreting CD4+CD25+ FOXP3+ T regulatory cells in anergic lepromatous leprosy patients. PLoS Negl Trop Dis 8: e2639.

41. Williams ME, Caspar P, Oswald I, Sharma HK, Pankewycz O, et al. (1995) Vaccination routes that fail to elicit protective immunity against Schistosoma mansoni induce the production of TGF-beta, which downregulates macrophage antiparasitic activity. J Immunol 154: 4693-4700.

42. Soong L, Duboise SM, Kima P, McMahon-Pratt D (1995) Leishmania pifanoi amastigote antigens protect mice against cutaneous leishmaniasis. Infect Immun 63: 3559-3566.

43. Colmenares M, Tiemeyer M, Kima P, McMahon-Pratt D (2001) Biochemical and biological characterization of the protective Leishmania pifanoi amastigote antigen P-8. Infect Immun 69: 6776-6784.

44. Rafati S, Salmanian AH, Taheri T, Masina S, Schaff C, et al. (2004) Type I signal peptidase from Leishmania is a target of the immune response in human cutaneous and visceral leishmaniasis. Mol Biochem Parasitol 135: 13-20.

45. Rafati S, Ghaemimanesh F, Zahedifard F (2006) Comparison of potential protection induced by three vaccination strategies (DNA/DNA, Protein/ protein and DNA/protein) against Leishmania major infection using signal peptidase type I in BALB/c mice. Vaccine 24: 3290-3297.

46. De Matos-Guedes HL, da Silva-Costa BL, Chaves SP, de Oliveira-Gomes DC, Nosanchuk JD, et al. (2014) Intranasal vaccination with extracellular serine 2 proteases of Leishmania amazonensis confers protective immunity to BALB/c 3 mice against infection. Parasit Vectors 7: 448 .

47. Choudhury R, Das P, De T, Chakraborti T (2013) $115 \mathrm{kDa}$ serine protease confers sustained protection to visceral leishmaniasis caused by Leishmania donovani via IFN- $\gamma$ induced down-regulation of TNF- $\alpha$ mediated MMP-9 activity. Immunobiology 218: 114-126. 